\title{
PTEN Mutations as a Cause of Constitutive Insulin Sensitivity and Obesity
}

\author{
Aparna Pal, M.R.C.P., Thomas M. Barber, D.Phil., M.R.C.P., Martijn Van de Bunt, M.D., \\ Simon A. Rudge, Ph.D., Qifeng Zhang, Ph.D., Katherine L. Lachlan, M.R.C.P.C.H., Nicola S. \\ Cooper, M.R.C.P., Helen Linden, M.R.C.P., Jonathan C. Levy, M.D., F.R.C.P., Michael J.O. \\ Wakelam, Ph.D., Lisa Walker, D.Phil., M.R.C.P.C.H., Fredrik Karpe, Ph.D., F.R.C.P., and \\ Anna L. Gloyn, D.Phil \\ Oxford Centre for Diabetes Endocrinology and Metabolism, University of Oxford, Oxford (A.P., \\ T.M.B., M.V.B., J.C.L., F.K., A.L.G.); the Oxford National Institute for Health Research Biomedical \\ Research Centre (A.P., J.C.L., F.K., A.L.G.) and the Oxford Regional Genetics Centre (H.L., \\ L.W.), Churchill Hospital, Oxford; the Inositide Laboratory, the Babraham Institute, Babraham, \\ Cambridge (S.A.R., Q.Z., M.J.O.W.); Wessex Clinical Genetics Service, University Hospital \\ Southampton, Southampton (K.L.L.); the Department of Human Genetics and Genomic Medicine, \\ Faculty of Medicine, University of Southampton, Southampton (K.L.L.); and West Midlands \\ Regional Clinical Genetics Service, Birmingham Women's Hospital, Birmingham (N.S.C.) - all in \\ the United Kingdom.
}

\section{Abstract \\ BACKGROUND—Epidemiologic and genetic evidence links type 2 diabetes, obesity, and cancer. The tumor-suppressor phosphatase and tensin homologue (PTEN) has roles in both cellular growth and metabolic signaling. Germline PTEN mutations cause a cancer-predisposition syndrome, providing an opportunity to study the effect of PTEN haploinsufficiency in humans.}

METHODS-We measured insulin sensitivity and beta-cell function in 15 PTEN mutation carriers and 15 matched controls. Insulin signaling was measured in muscle and adipose-tissue biopsy specimens from 5 mutation carriers and 5 well-matched controls. We also assessed the effect of PTEN haploinsufficiency on obesity by comparing anthropometric indexes between the 15 patients and 2097 controls from a population-based study of healthy adults. Body composition was evaluated by means of dual-emission x-ray absorptiometry and skinfold thickness.

RESULTS-Measures of insulin resistance were lower in the patients with a PTEN mutation than in controls (e.g., mean fasting plasma insulin level, 29 pmol per liter [range, 9 to 99] vs. 74 pmol per liter [range, 22 to 185]; $\mathrm{P}=0.001$ ). This finding was confirmed with the use of hyperinsulinemic euglycemic clamping, showing a glucose infusion rate among carriers 2 times that among controls $(\mathrm{P}=0.009)$. The patients' insulin sensitivity could be explained by the presence of enhanced insulin signaling through the PI3K-AKT pathway, as evidenced by

Copyright $@ 2012$ Massachusetts Medical Society.

Address reprint requests to Dr. Gloyn at the Oxford Centre for Diabetes Endocrinology and Metabolism, University of Oxford, Churchill Hospital, Headington, Oxford OX3 7LE, United Kingdom, or at anna.gloyn@drl.ox.ac.uk.

Disclosure forms provided by the authors are available with the full text of this article at NEJM.org. 
increased AKT phosphorylation. The PTEN mutation carriers were obese as compared with population-based controls (mean body-mass index [the weight in kilograms divided by the square of the height in meters], 32 [range, 23 to 42 ] vs. 26 [range, 15 to 48]; $\mathrm{P}<0.001$ ). This increased body mass in the patients was due to augmented adiposity without corresponding changes in fat distribution.

CONCLUSIONS-PTEN haploinsufficiency is a monogenic cause of profound constitutive insulin sensitization that is apparently obesogenic. We demonstrate an apparently divergent effect of PTEN mutations: increased risks of obesity and cancer but a decreased risk of type 2 diabetes owing to enhanced insulin sensitivity. (Funded by the Wellcome Trust and others.)

Epidemiologic evidence for a link among type 2 diabetes, obesity, and cancer has increased interest in the idea that some antidiabetes therapies may increase the risk of susceptibility to cancer, whereas others appear to offer protection. ${ }^{1}$ Such a link is also supported by the discovery of several susceptibility loci for type 2 diabetes and their unexpected proximity to genes implicated in cell-cycle regulation. ${ }^{2}$ The discovery of common genetic variants that influence both the risk of cancer and the risk of type 2 diabetes, in opposite directions, suggests that the two conditions may result from defects in the same pathway. ${ }^{3-5}$

Much of the overlap between type 2 diabetes and cancer has previously been explained by high circulating levels of insulin and insulin-like growth factor 1 (both of which are growth factors) that characterize insulin-resistant states such as type 2 diabetes. ${ }^{6}$ However, more recent pharmacologic evidence and genetic links point to alternative causes, such as the existence of enzymes and signaling pathways common to both cell cycling and metabolism. ${ }^{7}$

An example of this is the tumor-suppressor phosphatase and tensin homologue (PTEN), a protein and lipid phosphatase, which antagonizes the phosphatidylinositol 3-kinase (PI3K) pathway and also has a role in both the cell-cycle and metabolic pathways. ${ }^{7,8}$ PTEN (located on chromosome 10q23.3) is among the most common somatically mutated genes in tumorigenesis, and germline loss-of-function PTEN mutations cause the Cowden syndrome, a rare cancer-predisposition syndrome. ${ }^{9}$ PTEN has also been implicated in type 2 diabetes, since the PI3K-AKT pathway plays a role in insulin signaling. ${ }^{10}$ In mice lacking one copy of Pten, phosphorylation and activation of the pathway is increased, resulting in increased insulin sensitivity. ${ }^{11}$ Tissue-specific knockout of Pten in mice has been shown to affect liver, muscle, adipose tissue, and pancreatic beta cells to improve glucose tolerance. ${ }^{12-16}$ The Cowden syndrome provides a unique opportunity to study the effect of PTEN haploinsufficiency on insulin action in humans. Given the role of PTEN in both cell growth and metabolism, we hypothesized that persons lacking a functional copy of PTEN would be constitutively sensitive to insulin.

\section{METHODS \\ PATIENTS}

From 2007 through 2011, we recruited 15 patients with the Cowden syndrome, caused by loss-of-function PTEN mutations, through the U.K. Clinical Genetics Network (Table 1 in the Supplementary Appendix, available with the full text of this article at NEJM.org). This 
study was approved by the Oxfordshire Regional Ethics Committee B. All study participants (the patients and some unaffected siblings and spouses) provided written informed consent.

All mutations ( 7 nonsense mutations, 2 deletions, and 6 missense mutations) were ascertained at a certified molecular genetics diagnostic laboratory. All missense mutations were located in the exons encoding the catalytic domain of PTEN. All are expected to result in haploinsufficiency. ${ }^{17}$

All 15 patients had a clinical diagnosis of the Cowden syndrome. The two major criteria are macrocephaly and thyroid, breast, or endometrial carcinoma; the minor criteria are other thyroid lesions, mental retardation, gastrointestinal hamartomas, lipomas, fibrocystic disease of the breast, uterine fibroids, fibromas, and genitourinary tumors or malformations. A clinical diagnosis requires the presence of both major criteria, of one major criterion and three minor criteria, or of four minor criteria.

The patients were 18 to 80 years of age, had been free of cancer for at least 2 years, and were not taking any medication that could interfere with glucose tolerance (e.g., glucocorticoids). Two patients were first-degree relatives (siblings); no other individuals were known to be related. Fifteen healthy volunteers were recruited from the Oxford BioBank (www.oxfordbiobank.org.uk) and other control databases available in our department. The controls were matched to the patients according to age, sex, and body-mass index (BMI). All controls were negative for PTEN mutations. All patients and controls were white Europeans.

\section{BIOCHEMICAL ASSAYS}

Oral Glucose-Tolerance Testing-All participants underwent a 75-g oral glucosetolerance test (OGTT) after fasting for 12 hours. In fasting blood samples we measured levels of lipids, adiponectin, and leptin, and in blood samples obtained at 0, 30, 60, 90 and 120 minutes after oral glucose loading we measured plasma glucose and serum insulin levels. (Details of all biochemical assays can be found in the Supplementary Appendix.)

Insulin resistance was estimated from the OGTT result and the fasting insulin level, the area under the curve (AUC) for insulin, the homeostasis model assessment (HOMA) of insulin resistance, the Matsuda index,${ }^{18}$ the Stumvoll index,${ }^{19}$ and a hyperinsulinemic euglycemic clamp. ${ }^{20}$ Beta-cell function was estimated on the basis of the disposition index, which adjusts insulin secretion for the degree of insulin resistance as measured by dividing the insulinogenic index by the HOMA of insulin resistance, with the insulinogenic index calculated as the ratio of incremental insulin to incremental glucose response during the first 30 minutes of the OGTT. ${ }^{21}$ Data on glycemic traits were contributed by the Meta-Analysis of Glucose and Insulin Related Traits Consortium (MAGIC) investigators ${ }^{2}$ (by means of download from www.magicinvestigators.org).

Hyperinsulinemic Euglycemic Clamping-A primed, continuous insulin infusion was administered for the 120 minutes of the clamping. ${ }^{22}$ Glucose concentrations were monitored at 5-minute intervals for adjustment of the rate of infusion of $20 \%$ glucose to maintain euglycemia (90 mg per deciliter [5.0 mmol per liter]). 


\section{ANTHROPOMORPHIC DATA}

The anthropomorphic data for each participant were compared with the data for 8 to 10 population controls from a database of 1781 currently available scans from a populationbased study of healthy men and women. Each control was carefully matched on the basis of age (within 2 years), BMI (within 1 unit), and sex.

The BMI was calculated as the weight in kilograms divided by the square of the height in meters; waist and hip circumferences were measured and the waist-to-hip ratio was calculated. Body fat was measured by means of bioimpedance (Bodystat 500 analyzer, Bodystat). Body composition was measured for 6 of the 15 patients and the population controls with the use of dual-emission x-ray absorptiometry (Lunar iDXA, GE Healthcare). Default settings were used to define the limits for android and gynoid fat masses.

We obtained adipose-tissue and skeletal-muscle biopsy specimens from five patients and five controls. Skeletal-muscle biopsy specimens were obtained from the vastus lateralis muscle of patients in the fasting state, under local anesthesia, with the use of a modified Bergström needle and suction. Subcutaneous abdominal adipose tissue was obtained under local anesthesia by means of a 14-gauge sterile needle (Sterican) at 0 and 120 minutes of an OGTT. The tissue samples were immediately frozen in liquid nitrogen and stored at $-80^{\circ} \mathrm{C}$. Immunoblot analysis was performed to ascertain levels of AKT, phosphorylated AKT, phosphatidylinositol 4,5-bisphosphate ( $\left.\mathrm{PIP}_{2}\right)$, and phosphatidylinositol (3,4,5)-triphosphate ( $\mathrm{PIP}_{3}$ ), and PTEN messenger RNA (mRNA) was assayed in the adipose- and muscle-tissue specimens (see the Supplementary Appendix for details).

\section{STATISTICAL ANALYSIS}

All analyses were performed with the use of SPSS software (version 20.0). Given the small sample sizes and the non-normal distribution of the data, nonparametric tests were performed for all comparisons. We used a two-tailed Mann-Whitney $\mathrm{U}$ test to analyze the clinical data (including results from the OGTT, clamping, and dual-emission x-ray absorptiometry); all $\mathrm{P}$ values are two-sided. We carried out linear regression analysis of the $\log _{10}$-transformed BMI data for the patients and their unaffected siblings and spouses to correct informally for age and sex (without the use of matched groups). The Wilcoxon signed-rank test (two-tailed) was used for all comparisons of AKT and phosphorylated AKT levels in specimens of muscle and adipose tissue.

\section{RESULTS}

Table 1 shows the baseline characteristics of the 15 study patients and the 15 sex-, age-, and BMI-matched controls, as well as their OGTT results. None of the patients had diabetes; 1 had impaired fasting glycemia but normal glucose tolerance (2-hour glucose level, $95 \mathrm{mg}$ per deciliter [ $5.3 \mathrm{mmol}$ per liter]). The glucose increment in the 2 hours after the glucose challenge did not differ significantly between the patients and controls (Table 1 and Fig. $1 \mathrm{~A})$.

All measures of insulin resistance were significantly lower, and all measures of insulin sensitivity were significantly higher, in the PTEN-mutation carriers than in controls. The 
fasting insulin level was $60 \%$ lower among patients than among controls $(\mathrm{P}=0.001)$; the AUC for insulin, 67\% lower $(\mathrm{P}<0.001)$; and the HOMA of insulin resistance, 59\% lower ( $\mathrm{P}$ $=0.001)($ Fig. 1A). With regard to insulin sensitivity, the Stumvoll index score in the patient group was 1.67 times the score in the control group $(\mathrm{P}=0.02)$, and the Matsuda index score was 2.2 times greater among patients than among controls $(\mathrm{P}=0.001)$ (Table 1$)$.

Hyperinsulinemic euglycemic clamp studies were performed in 5 of the 15 patients and 5 of the 15 controls matched for age, sex, BMI, and physical activity. The findings confirmed that the patients had higher insulin sensitivity $(P=0.009)$ (Fig. 1B). The International Diabetes Federation criteria for the diagnosis of metabolic syndrome ${ }^{23}$ were met by 2 of the 15 patients (13\%) and 2 of the 15 controls (13\%). Removal of either of the 2 related patients (siblings) with the Cowden syndrome from the analysis did not alter the levels of significance of any variable measured.

To further evaluate the relationship between insulin sensitivity and BMI, we plotted fasting insulin levels against BMI for the patients and for 2097 population-based controls. The patients and controls were well matched regarding both sex (with $47 \%$ and $49 \%$ men, respectively) and age (mean, 44 years [range, 29 to 62] and 41 years [range, 29 to 53], respectively).

The patient data were clustered around the 5th percentile of the control data (i.e., at the lower end of the normal range of fasting insulin levels, given their BMI) (Fig. 2A). The regression slopes between fasting insulin and BMI were parallel between the patients with the Cowden syndrome and the background population (Fig. 2A). Thus, the absolute increase in insulin level per unit of BMI was similar across the range of BMIs in each of the two groups yet overall was less in the PTEN-mutation carriers, and fasting normoglycemia could be maintained in the PTEN-mutation carriers with a significantly lower output of insulin, consistent with the higher insulin sensitivity of this group. Beta-cell function, as measured by the disposition index, was not significantly different between the 15 patients and the 15 controls (Table 1). The patients with the Cowden syndrome had an elevated BMI (mean, 32 [range, 23 to 42]) as compared with a large population-based control cohort ( $\mathrm{P}<0.001)$ (Fig. 2B).

We wondered whether elevated BMI was a feature of the Cowden syndrome per se. To investigate this, we identified six additional PTEN-mutation carriers from the U.K. Clinical Genetics Network and found that their BMIs were also elevated (mean, 32 [range, 24 to 43]). Moreover, our patients' BMIs were greater than those of unaffected, noncarriers: 18 siblings (mean, 25 [range, 20 to 34]; $\mathrm{P}=0.001$ ) and 11 spouses (mean, 27 [range, 22 to 34]; $\mathrm{P}=0.004$ ). (See Fig. 1 in the Supplementary Appendix for data from the largest single pedigree including a patient with the Cowden syndrome in our study.) To describe the nature of the increased weight in the PTEN-mutation carriers, we obtained anthropometric measurements (Table 1) and, in a subgroup of patients, results of dual-emission x-ray absorptiometry (Table 2 in the Supplementary Appendix). We found no significant differences between our patients and the controls matched for age, sex, and BMI with respect to lean body mass $(\mathrm{P}=0.49)$, bone mineral content $(\mathrm{P}=0.94)$, or total fat $(\mathrm{P}=1.00)$ or fat distribution (Table 2 in the Supplementary Appendix). 
One patient had data on her early growth: the birth weight was $4.4 \mathrm{~kg}$ (98th percentile); the birth length, $56 \mathrm{~cm}$ (99th percentile); and the head circumference, $39 \mathrm{~cm}$ (above the 99th percentile). During her first year of life she steadily gained weight, remaining consistently at the 98th percentile for her age. From 12 through 16 years, the BMI was above the 85th percentile for age. At the age of 21 years, the patient was overweight (BMI, 26.1). These data are consistent with a report ${ }^{24}$ of markedly increased weight gain relative to height, resulting in obesity, in children and adolescents with PTEN mutations.

To further investigate the role of PTEN in adipose tissue, we assayed two adipokines, adiponectin and leptin (Table 1). The total fasting plasma adiponectin level was significantly lower in the patients than in the controls $(\mathrm{P}<0.001)$, with no significant difference in the fasting plasma leptin level or lipid profile between the two groups (Table 1).

To determine whether increased insulin sensitivity in our patients with PTEN haploinsufficiency was associated with amplified insulin signaling through the PI3K-AKT pathway, we assayed the $\mathrm{PIP}_{3}$ levels in muscle tissue, and the extent of AKT phosphorylation in muscle and adipose tissue, by using biopsy specimens from the patients and the matched controls. In the fasting state, despite markedly lower circulating insulin levels in the patients than in the controls, the two groups had similar muscle $\mathrm{PIP}_{3}$ levels. The two groups were also similar in the total lipid mass and the $\mathrm{PIP}_{3}: \mathrm{PIP}_{2}$ ratio (which corrects for variation in cellular membranes across samples) (Table 3 in the Supplementary Appendix).

In addition, AKT levels were similar in the muscle-biopsy samples of each of the two groups. Lower, albeit not significantly lower, phosphorylated AKT levels were found in four of the five samples from patients as compared with their well-matched controls (Fig. 3A and 3B). In contrast, phosphorylated AKT levels in adipose-tissue samples were higher, albeit not significantly so, in three fasting patients as compared with their matched controls (Fig. $3 \mathrm{C}$ and 3D). AKT phosphorylation increased after stimulation with glucose in adipose tissue in both groups (Fig. 3C and 3D). Consistent with these data, PTEN mRNA levels were lower in both fasting adipose and muscle tissue from PTEN-haploinsufficient patients than in matched controls, although this finding was significant only in the adipose samples $(\mathrm{P}<0.05)$ (Fig. 3 in the Supplementary Appendix). Taken together, these data support enhanced signaling through the PI3K-AKT pathway in patients with PTEN haploinsufficiency.

\section{DISCUSSION}

Our patients with a cancer-predisposition syndrome due to loss-of-function mutations in the tumor suppressor PTEN are sensitized to insulin, as we hypothesized and as is consistent with a case report. ${ }^{25}$ Fasting insulin levels were significantly lower in the PTEN-mutation carriers than in controls; because the liver is the principal insulin-responsive tissue, the fasting insulin level predominantly reflects insulin resistance in the liver. We also observed a significant association between PTEN haploinsufficiency and increased insulin sensitivity of muscle tissue. Our findings show that PTEN deficiency enhances insulin signaling in both muscle and liver tissue in humans, possibly by way of its action on the PI3K-AKT pathway. 
Patients and controls in the fasting state had similar levels of $\mathrm{PIP}_{3}$ in muscle tissue, despite the significantly lower circulating stimulatory insulin levels in patients, revealing an association between amplified PI3K signaling and PTEN haploinsufficiency. Furthermore, AKT phosphorylation was greater in adipose tissue from the fasting patients than adipose tissue from controls, along with a reduced rate of $\mathrm{PIP}_{3}$-phosphatase activity. These findings also support enhanced insulin sensitivity caused by haploinsufficiency of PTEN. The higher levels of AKT phosphorylation in adipose tissue but not muscle tissue after fasting in patients versus controls indicate that adipose tissue may govern insulin sensitivity in the fasting state. This is consistent with the notion that adipose tissue is exquisitely sensitive to insulin. ${ }^{26}$ Our data are also supported by studies in rodents showing tissue-specific roles of Pten in liver, muscle, and adipose tissue and increased phosphorylation and activation of components of the PI3K-AKT pathway in Pten-haploinsufficient mice. ${ }^{12,14,16}$ These studies in rodents have also suggested dominant roles for Pten in both muscle and adipose tissue in insulin-sensitive phenotypes. ${ }^{12,16}$

In contrast to data obtained from mice with Pten-deficient beta cells, but consistent with those obtained from mice constitutively haploinsufficient for Pten $\left(\mathrm{Pten}^{+/-}\right.$mice), our data do not support increased beta-cell function or insulin secretion in PTEN-mutation carriers. ${ }^{13,15}$ The complexity of the dual roles of PTEN in growth and metabolism are illustrated by the effects of systemic PTEN elevation in mice. ${ }^{27}$ "Super-PTEN" mutant mice, which have elevated levels of PTEN expression, have reduced body fat accumulation and body size and increased energy expenditure. ${ }^{27}$

Our patients with PTEN mutations are apparently clinically significantly overweight and yet have markedly higher insulin sensitivity than matched controls. Our results show that this increase in body mass is not attributable to increased bone or lean mass but rather to an increase in adiposity. Also, the skinfold thickness (a specific measure of subcutaneous adipose tissue) was not significantly greater in the patients than in the weight-matched controls; compartmentalization of visceral fat into subcutaneous fat could have been related to increased insulin sensitivity. Furthermore, the increased insulin sensitivity in patients with PTEN haploinsufficiency cannot be attributed to an increase in the amount of metabolically protective gluteofemoral fat. Although systematic measurements of height and weight throughout childhood and adolescence were not available for the majority of our patients, the data that we were able to obtain, together with previously reported data, ${ }^{25}$ suggest that there is a steady increase in weight throughout childhood and adolescence in PTENmutation carriers.

Adiponectin is associated with insulin sensitivity, and insulin-sensitive obese persons have elevated circulating adiponectin levels as compared with insulin-resistant obese persons. ${ }^{28}$ Despite the marked insulin sensitivity in our patients as compared with controls, the circulating adiponectin levels were paradoxically lower. Adiponectin levels were correlated with the BMI in both groups but were consistently lower across BMI units among the patients than among the controls (Fig. 2 in the Supplementary Appendix). Findings were similar for the waist-to-hip ratio (data not shown). 
The relationship between adiponectin and insulin sensitivity is complex, and others have found unexpected results when measuring this hormone in relation to insulin resistance syndromes. Patients with severe insulin resistance due to genetically defective insulin receptors have hyperadiponectinemia. ${ }^{29}$ In the Cowden syndrome, the relationship between insulin sensitivity and adiponectin is further complicated by the link between adiponectin levels and the risk of cancer. ${ }^{30}$ Circulating adiponectin levels have been shown to be inversely associated with the risk of breast or endometrial cancer, among others, which are common in the Cowden syndrome. ${ }^{31}$

We also tested for an association between common genetic variation at the PTEN locus and measures of fasting glucose or insulin in healthy, nondiabetic controls. We examined singlenucleotide polymorphisms in or within $1 \mathrm{~kb}$ of PTEN in the publicly available data from MAGIC. ${ }^{2}$ Although no variant reached genomewide significance $\left(\mathrm{P}=5 \times 10^{-8}\right)$, we found suggestive associations for both fasting insulin ( $\left(\mathrm{rs} 2142136, \mathrm{P}=1.17 \times 10^{-5}\right)$ and fasting glucose levels $\left(\mathrm{rs} 11202614, \mathrm{P}=7.13 \times 10^{-7}\right){ }^{2}$ These preliminary findings will require further replication, and given the inverse relationship between fasting insulin levels and BMI in patients with the Cowden syndrome, it would be sensible to reanalyze with adjustment of fasting insulin levels for BMI.

In conclusion, we describe a monogenic cause of profound insulin sensitization that paradoxically occurs in association with adiposity. We also demonstrate that PTEN haploinsufficiency appears to result in an increased risk of obesity and cancer but a decreased risk of type 2 diabetes, owing to enhanced insulin sensitivity. This exemplifies how intimately pathways in metabolism and cell growth may be linked and lends support to the hypothesis that the epidemiologic and genetic associations between cancer and type 2 diabetes may be based on common signaling pathways linking tumor-suppressor genes to metabolic pathways that mediate insulin action.

\section{Supplementary Material}

Refer to Web version on PubMed Central for supplementary material.

\section{Acknowledgments}

Supported by grants from the Wellcome Trust (095101/Z/10Z, to Dr. Gloyn), the Medical Research Council (G0700222, to Dr. Gloyn; and G0800467, to Drs. Pal and Gloyn), the National Institute for Health Research Oxford Biomedical Research Centre (to Drs. Pal, Karpe, and Gloyn), the Biotechnology and Biological Sciences Research Council (to Drs. Rudge, Zhang, and Wakelam), and the European Union Seventh Framework Program LipodomicNet (202272, for adipocyte signaling work, to Drs. Wakelam and Karpe).

We thank the clinicians Trevor R.P. Cole, Louise Izatt, Carole McKeown, Eamonn R. Maher, and Mary Porteous for referring patients for this study; the research nurses Beryl Barrow and Jane Cheeseman for assistance with collecting clinical data; Amy Barrett for analysis of PTEN expression; Sandy Humphries for analysis of apolipoprotein B; Tim James and colleagues at the John Radcliffe Hospital, Oxford, for analysis of glucose and insulin; the NIHR Cambridge Biomedical Research Centre Core Biochemical Assay Laboratory for analysis of leptin and adiponectin; Leanne Hodson and Barbara Fielding for access to control dual-emission x-ray absorptiometry scans and phenotypic data on postmenopausal controls; and Jonathan Clark and Izabella Niewczas for providing lipid standards for the mass-spectrometry analysis. 


\section{REFERENCES}

1. Smith U, Gale EA. Cancer and diabetes: are we ready for prime time? Diabetologia. 2010; 53:15414. [PubMed: 20549181]

2. Dupuis J, Langenberg C, Prokopenko I, et al. New genetic loci implicated in fasting glucose homeostasis and their impact on type 2 diabetes risk. Nat Genet. 2010; 42:105-16. [PubMed: 20081858] Erratum Nat Genet. 2010; 42:464.

3. Gudmundsson J, Sulem P, Steinthorsdottir V, et al. Two variants on chromo-some 17 confer prostate cancer risk, and the one in TCF2 protects against type 2 diabetes. Nat Genet. 2007; 39:97783. [PubMed: 17603485]

4. Agalliu I, Suuriniemi M, Prokunina-Olsson L, et al. Evaluation of a variant in the transcription factor 7-like 2 (TCF7L2) gene and prostate cancer risk in a population-based study. Prostate. 2008; 68:740-7. [PubMed: 18302196]

5. Thomas G, Jacobs KB, Yeager M, et al. Multiple loci identified in a genome-wide association study of prostate cancer. Nat Genet. 2008; 40:310-5. [PubMed: 18264096]

6. Holly JM, Perks CM. Cancer as an endocrine problem. Best Pract Res Clin Endocrinol Metab. 2008; 22:539-50. [PubMed: 18971117]

7. Goberdhan DC, Wilson C. PTEN: tumour suppressor, multifunctional growth regulator and more. Hum Mol Genet. 2003; 12(Spec No 2):R239-R248. [PubMed: 12928488]

8. Maehama T, Dixon JE. The tumor suppressor, PTEN/MMAC1, dephosphorylates the lipid second messenger, phosphatidylinositol 3,4,5-trisphosphate. J Biol Chem. 1998; 273:13375-8. [PubMed: 9593664]

9. Blumenthal GM, Dennis PA. PTEN hamartoma tumor syndromes. Eur J Hum Genet. 2008; 16:1289-300. [PubMed: 18781191]

10. Cohen P. The twentieth century struggle to decipher insulin signalling. Nat Rev Mol Cell Biol. 2006; 7:867-73. [PubMed: 17057754]

11. Wong JT, Kim PT, Peacock JW, et al. Pten (phosphatase and tensin homologue gene) haploinsufficiency promotes insulin hypersensitivity. Diabetologia. 2007; 50:395-403. [PubMed: 17195063]

12. Kurlawalla-Martinez C, Stiles B, Wang Y, Devaskar SU, Kahn BB, Wu H. Insulin hypersensitivity and resistance to streptozotocin-induced diabetes in mice lacking PTEN in adipose tissue. Mol Cell Biol. 2005; 25:2498-510. [PubMed: 15743841]

13. Nguyen KT, Tajmir P, Lin CH, et al. Essential role of Pten in body size determination and pancreatic beta-cell homeostasis in vivo. Mol Cell Biol. 2006; 26:4511-8. [PubMed: 16738317]

14. Stiles B, Wang Y, Stahl A, et al. Liver-specific deletion of negative regulator Pten results in fatty liver and insulin hypersensitivity. Proc Natl Acad Sci U S A. 2004; 101:2082-7. [PubMed: 14769918] Erratum Proc Natl Acad Sci U S A. 2004; 101:5180.

15. Stiles BL, Kuralwalla-Martinez C, Guo W, et al. Selective deletion of Pten in pancreatic beta cells leads to increased islet mass and resistance to STZ-induced diabetes. Mol Cell Biol. 2006; 26:2772-81. [PubMed: 16537919]

16. Wijesekara N, Konrad D, Eweida M, et al. Muscle-specific Pten deletion protects against insulin resistance and diabetes. Mol Cell Biol. 2005; 25:1135-45. [PubMed: 15657439]

17. Berger AH, Knudson AG, Pandolfi PP. A continuum model for tumour suppression. Nature. 2011; 476:163-9. [PubMed: 21833082]

18. Matsuda M, DeFronzo RA. Insulin sensitivity indices obtained from oral glucose tolerance testing: comparison with the euglycemic insulin clamp. Diabetes Care. 1999; 22:1462-70. [PubMed: 10480510]

19. Stumvoll M, Mitrakou A, Pimenta W, et al. Use of the oral glucose tolerance test to assess insulin release and insulin sensitivity. Diabetes Care. 2000; 23:295-301. [PubMed: 10868854]

20. Levy JC, Matthews DR, Hermans MP. Correct homeostasis model assessment (HOMA) evaluation uses the computer program. Diabetes Care. 1998; 21:2191-2. [PubMed: 9839117] 
21. Phillips DI, Clark PM, Hales CN, Osmond C. Understanding oral glucose tolerance: comparison of glucose or insulin measurements during the oral glucose tolerance test with specific measurements of insulin resistance and insulin secretion. Diabet Med. 1994; 11:286-92. [PubMed: 8033528]

22. DeFronzo RA, Tobin JD, Andres R. Glucose clamp technique: a method for quantifying insulin secretion and resistance. Am J Physiol. 1979; 237:E214-E223. [PubMed: 382871]

23. Alberti KG, Zimmet P, Shaw J. The metabolic syndrome - a new worldwide definition. Lancet. 2005; 366:1059-62. [PubMed: 16182882]

24. Cole TR, Hughes HE. Autosomal dominant macrocephaly: benign familial macrocephaly or a new syndrome? Am J Med Genet. 1991; 41:115-24. [PubMed: 1719811]

25. Iida S, Ono A, Sayama K, et al. Accelerated decline of blood glucose after intravenous glucose injection in a patient with Cowden disease having a heterozygous germline mutation of the PTEN/ MMAC1 gene. Anticancer Res. 2000; 20:1901-4. [PubMed: 10928124]

26. Karpe F, Tan GD. Adipose tissue function in the insulin-resistance syndrome. Biochem Soc Trans. 2005; 33:1045-8. [PubMed: 16246042]

27. Garcia-Cao I, Song MS, Hobbs RM, et al. Systemic elevation of PTEN induces a tumorsuppressive metabolic state. Cell. 2012; 149:49-62. [PubMed: 22401813]

28. Klöting N, Fasshauer M, Dietrich A, et al. Insulin-sensitive obesity. Am J Physiol Endocrinol Metab. 2010; 299:E506-E515. [PubMed: 20570822]

29. Semple RK, Soos MA, Luan J, et al. Elevated plasma adiponectin in humans with genetically defective insulin receptors. J Clin Endocrinol Metab. 2006; 91:3219-23. [PubMed: 16705075]

30. Wei EK, Giovannucci E, Fuchs CS, Willett WC, Mantzoros CS. Low plasma adiponectin levels and risk of colorectal cancer in men: a prospective study. J Natl Cancer Inst. 2005; 97:1688-94. [PubMed: 16288122]

31. Barb D, Pazaitou-Panayiotou K, Mantzoros CS. Adiponectin: a link between obesity and cancer. Expert Opin Investig Drugs. 2006; 15:917-31. 


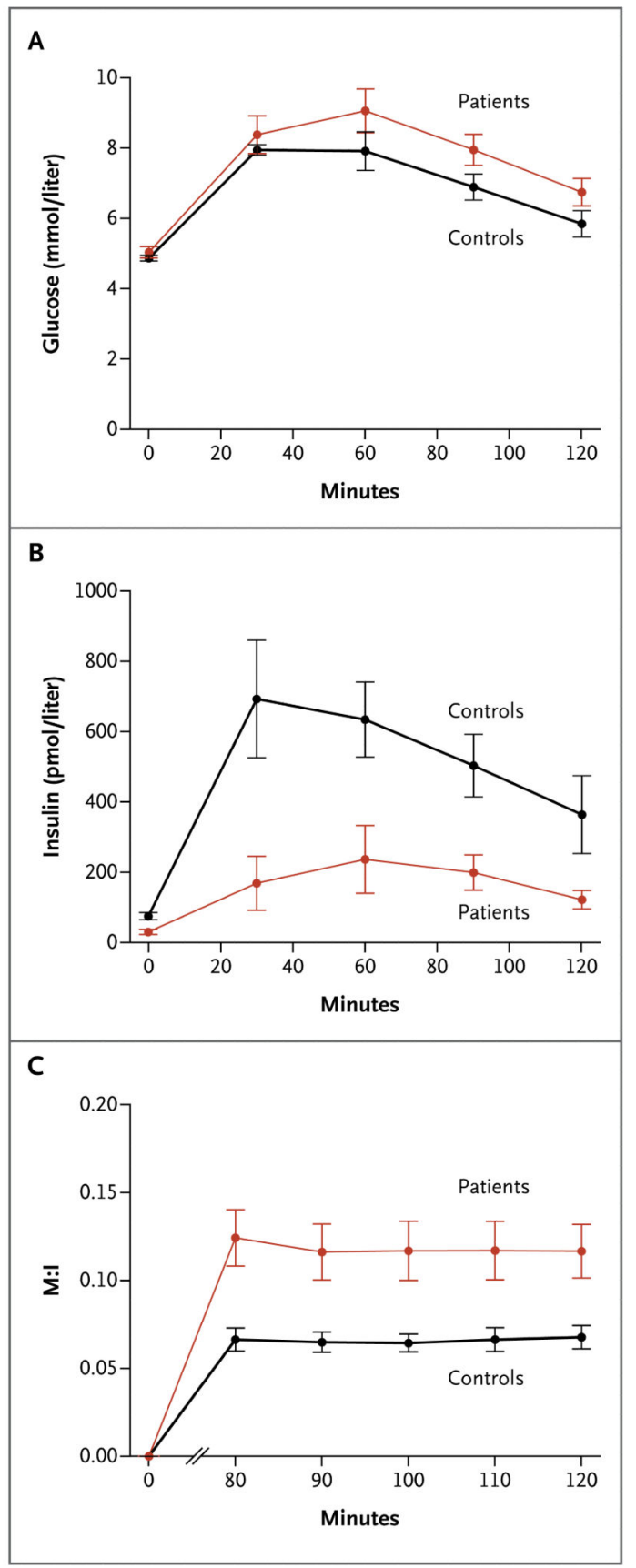

Figure 1. Glucose Tolerance and Insulin Sensitivity from the Oral Glucose-Tolerance Test (OGTT) and Clamp Studies in Five Patients with Loss-of-Function PTEN Mutations and Five Controls

Panel A and Panel B show the mean glucose and insulin levels, respectively, during an OGTT. Panel C shows the mean M:I ratio from hyperinsulinemic euglycemic clamp studies; the $\mathrm{M}$ component (milligrams per kilogram of body weight per minute) was calculated from the mean $20 \%$ glucose infusion rate (in milliliters per hour), and the I component was the ambient insulin concentration (milliunits per liter). The data are means across all 15 patients or controls in Panels A and B but across only 5 patients or controls in Panel C. To convert 
values for glucose to milligrams per deciliter, divide by 0.05551 . I bars indicate standard errors. 


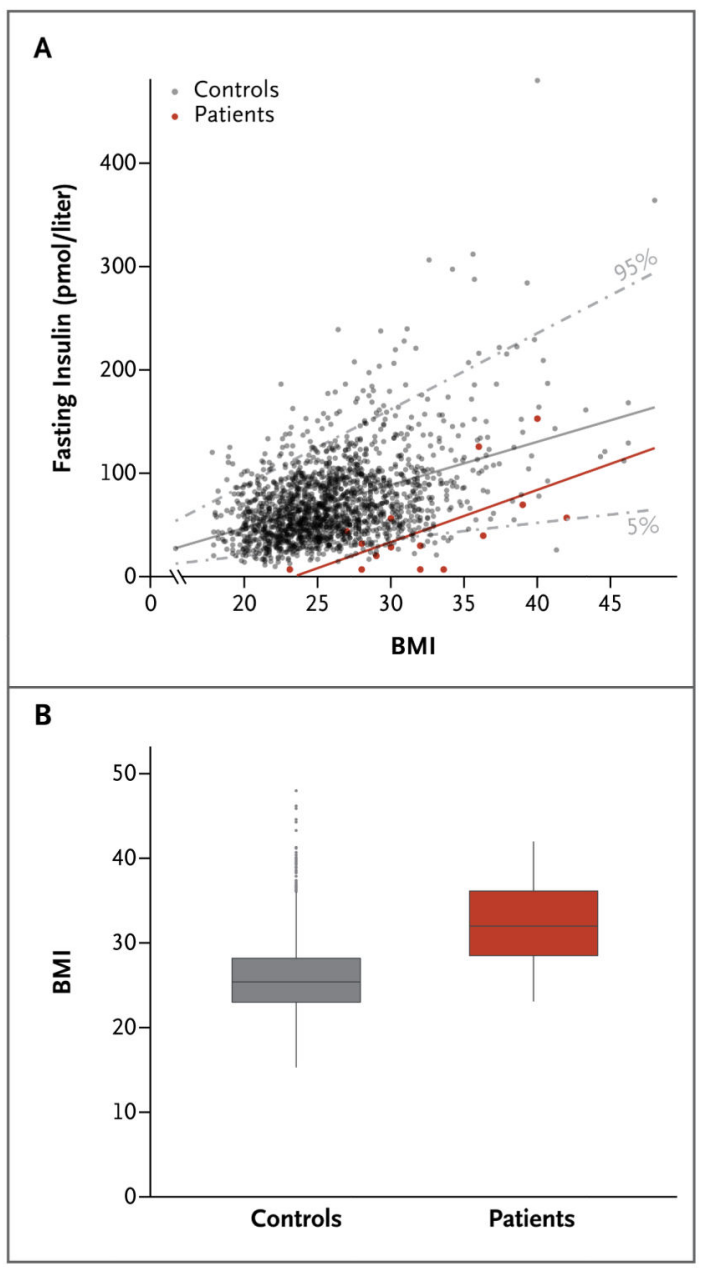

Figure 2. Assessment of Insulin Sensitivity and the Body-Mass Index (BMI) in the 15 Patients and 2097 Population-Based Controls

Panel A shows the relationship between fasting insulin levels and BMI, with adjustment for age and sex. The 5th and 95th percentiles for the controls are shown as gray dashed lines; the regression slopes between fasting insulin and BMI are shown as solid lines. Panel B shows BMI data for the patients (mean, 32 [range, 23 to 42]) and for the controls (mean, 26 [range, 15 to 48]). In the box-and-whisker plot, the horizontal line inside the box represents the median, the top and bottom of the box represent the interquartile range, and the vertical bars ("whiskers") represent the range; outliers are shown as individual data points. 


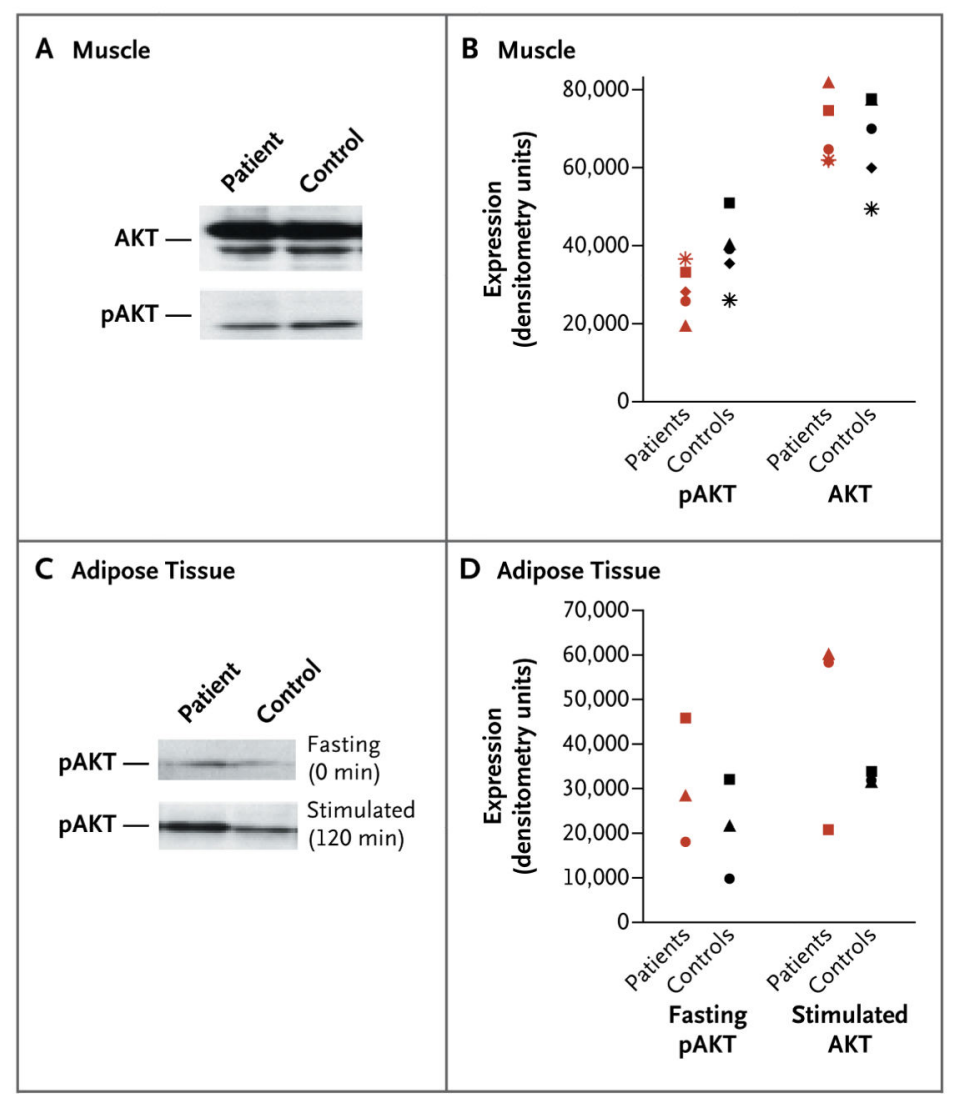

Figure 3. AKT Phosphorylation Status in Muscle and Adipose-Tissue Specimens in Five Study Patients and Five Controls

Panel A shows a representative blot of relative AKT and phosphorylated AKT (pAKT) levels in muscle tissue from a patient and a matched control, both in a fasting state. Panel B shows the protein expression levels for AKT and pAKT in muscle tissue in five patients and five controls (between-group $\mathrm{P}=0.14$ for $\mathrm{AKT}$ and $\mathrm{P}=0.69$ for $\mathrm{pAKT}$, by a two-tailed Wilcoxon signed-rank test). Panel $\mathrm{C}$ shows a representative blot of relative pAKT levels in adipose tissue from a patient and a control in the fasting state (at 0 minutes) and the glucosestimulated state (at 120 minutes after the oral glucose-tolerance test was begun). Panel D shows pAKT expression in adipose tissue from three patients and three controls before and after stimulation with glucose (between-group $\mathrm{P}=0.11$ and $\mathrm{P}=0.28$, respectively, by a twotailed Wilcoxon signed-rank test). (The remaining two samples in each group were not analyzed, owing to insufficient material resulting from technical difficulties.) 
Table 1

Baseline Characteristics of the Study Patients and Controls.

\begin{tabular}{|c|c|c|c|}
\hline Characteristic & PTEN Mutation Carriers ( $\mathrm{N}=15)$ & Controls $(\mathrm{N}=15)$ & P Value \\
\hline Male sex $(\%)$ & 47 & 47 & 1.00 \\
\hline Age (yr) & & & 0.59 \\
\hline Geometric mean & 44 & 45 & \\
\hline Range & $29-62$ & $34-67$ & \\
\hline Body-mass index & & & 0.51 \\
\hline Geometric mean & 32 & 31 & \\
\hline Range & $23-42$ & $23-40$ & \\
\hline \multicolumn{4}{|l|}{ Body fat (\%) } \\
\hline Men & & & 0.13 \\
\hline Geometric mean & 27 & 35 & \\
\hline Range & $15-34$ & $28-44$ & \\
\hline Women & & & 0.57 \\
\hline Geometric mean & 37 & 35 & \\
\hline Range & $20-51$ & $22-47$ & \\
\hline \multicolumn{4}{|l|}{ Waist circumference $(\mathrm{cm})$} \\
\hline Men & & & 0.53 \\
\hline Geometric mean & 115 & 121 & \\
\hline Range & $85-136$ & $89-137$ & \\
\hline Women & & & 0.96 \\
\hline Geometric mean & 103 & 102 & \\
\hline Range & $92-126$ & $91-110$ & \\
\hline \multicolumn{4}{|l|}{ Waist-to-hip ratio } \\
\hline Men & & & 0.80 \\
\hline Geometric mean & 1.03 & 1.04 & \\
\hline Range & $0.80-1.15$ & $0.85-1.16$ & \\
\hline Women & & & 0.57 \\
\hline Geometric mean & 0.89 & 0.90 & \\
\hline Range & $0.85-0.93$ & $0.85-0.96$ & \\
\hline \multicolumn{4}{|l|}{ Blood pressure (mm Hg) } \\
\hline Systolic & & & 0.93 \\
\hline Geometric mean & 124 & 124 & \\
\hline Range & $104-136$ & $107-140$ & \\
\hline Diastolic & & & 0.57 \\
\hline Geometric mean & 75 & 73 & \\
\hline Range & $52-96$ & $60-86$ & \\
\hline Fasting glucose (mmol/liter) & & & 0.20 \\
\hline Geometric mean & 5.0 & 4.9 & \\
\hline Range & $4.2-6.9$ & $4.5-5.8$ & \\
\hline Fasting insulin (pmol/liter) & & & 0.001 \\
\hline Geometric mean & 29.2 & 74.3 & \\
\hline Range & $8.7-99.3$ & $22.1-184.6$ & \\
\hline AUC for insulin & & & $<0.001$ \\
\hline Geometric mean & 361 & 1095 & \\
\hline
\end{tabular}




\begin{tabular}{|c|c|c|c|}
\hline Characteristic & PTEN Mutation Carriers ( $\mathrm{N}=15)$ & Controls $(\mathrm{N}=15)$ & P Value \\
\hline Range & $102-1608$ & $350-2528$ & \\
\hline HOMA for insulin resistance & & & 0.001 \\
\hline Geometric mean & 6.5 & 16.0 & \\
\hline Range & $1.9-29.3$ & $5.0-40.2$ & \\
\hline Stumvoll index score & & & 0.02 \\
\hline Geometric mean & 0.10 & 0.06 & \\
\hline Range & $0.07-0.12$ & $0.02-0.12$ & \\
\hline Matsuda index score & & & 0.001 \\
\hline Geometric mean & 19.6 & 8.9 & \\
\hline Range & $6.3-54.1$ & $4.6-33.8$ & \\
\hline Insulinogenic index score & & & $<0.001$ \\
\hline Geometric mean & 47 & 199 & \\
\hline Range & $8-510$ & $91-512$ & \\
\hline Disposition index score & & & 0.89 \\
\hline Geometric mean & 187 & 128 & \\
\hline Range & $22-1509$ & $27-359$ & \\
\hline Adiponectin $(\mu \mathrm{g} / \mathrm{ml})$ & & & $<0.001$ \\
\hline Geometric mean & 3.6 & 6.2 & \\
\hline Range & $2.2-5.4$ & $3.0-35.4$ & \\
\hline Leptin (ng/ml) & & & 0.58 \\
\hline Geometric mean & 21.0 & 17.4 & \\
\hline Range & $1.3-84.8$ & $2.7-68.1$ & \\
\hline Triglycerides (mmol/liter) & & & 0.62 \\
\hline Geometric mean & 1.34 & 1.40 & \\
\hline Range & $0.74-2.64$ & $0.58-2.68$ & \\
\hline \multicolumn{4}{|l|}{ Cholesterol (mmol/liter) } \\
\hline Total & & & 0.13 \\
\hline Geometric mean & 4.9 & 5.3 & \\
\hline Range & $3.3-6.5$ & $3.6-6.8$ & \\
\hline HDL & & & 0.54 \\
\hline Geometric mean & 1.2 & 1.2 & \\
\hline Range & $0.9-1.7$ & $0.9-1.7$ & \\
\hline LDL & & & 0.07 \\
\hline Geometric mean & 3.4 & 3.9 & \\
\hline Range & $1.9-4.8$ & $2.3-5.4$ & \\
\hline Non-HDL & & & 0.07 \\
\hline Geometric mean & 3.7 & 4.2 & \\
\hline Range & $2.1-5.3$ & $2.5-5.6$ & \\
\hline Apolipoprotein B ( $\mathrm{g} /$ liter) & & & 0.27 \\
\hline Geometric mean & 0.95 & 0.88 & \\
\hline Range & $0.41-1.37$ & $0.50-1.14$ & \\
\hline
\end{tabular}

* $\mathrm{P}$ values were calculated with the use of the Mann-Whitney U test. In the Matsuda and Stumvoll indexes, higher values indicate greater insulin sensitivity, and in the HOMA (homeostasis model assessment) and insulinogenic indexes, higher values indicate greater insulin resistance. For all four indexes, the $95 \%$ confidence intervals for the control population provide the normal ranges. To convert values for glucose to milligrams per deciliter, divide by 0.05551 ; to convert values for cholesterol to milligrams per deciliter, divide by 0.02586 ; and to convert values for triglycerides to milligrams per deciliter, divide by 0.01129 . AUC denotes area under the trapezoidal curve, HDL high-density lipoprotein, LDL lowdensity lipoprotein, and PTEN tumor-suppressor phosphatase and tensin homologue. 